\title{
Inhibition of Carburisation by Gold Films
}

\author{
B. D. Whitley, P. C. Thornton and V. D. Scott \\ School of itaterials Science, University of Bath, England
}

Gold coatings have previously been explored as diffusion barriers

to protect chromum alloys against nitrdatzon, and substrate metals against hydrogen embrittlement during electroplating. It has now been demonstrated that they are effective as barriers against carburisation of steel. Moreover, considerable insight tnto their mode of action has been obtained.

One of the most popular processes for the heat-treatment of metais is that involving the carburisation of steel. When mild stcel is heated in an atmosphere rich in carbon monoxide, carbon deposits onto the steel surface, diffuses into the steel and establishes a carbon gradient from the surface inwards towards the core. The 'case depth' is a measure of the extent or thickness of the carbon-enriched surface layer. The hardness of a quenched steel relates directiy to its carbon content. Hence, subsequent quenching of a carburised steel causes the case to be very much harder than the uncarburised metal below it. This differential hardening markedly improves a component's woar and fatigue resistance.

Often, however, only certain parts of a component's surface arc required to be hard. In this situation, areas required soft are prevented from taking up carbon by a 'stopping off' treatment, usually by plating with copper. Many years of practical experience have shown that thin elcctrodeposited layers of copper, some $0.1 \mathrm{~mm}$ thick, act as a complete and impervious barrier to carbon penetration in all commercial carburising processes. Rccent researches have explained the reason for this useful attribute of copper (1).
All carburising operations are conducted at temperatures above the steel's critical temperature, that is, the temperature at which the atomic packing changes from body-centred cubic to face-centred cubic. Carbon atoms can rapidly dissolve in face-centred cubic iron to form an interstitial solid solution in which the carbon diffuses by movement from one interstitial site to another. Awareness of the size of the iron atoms allows calculation of the various interstice sizes in the face-centred cubic iron lattice as shown in the Table. These indicate that the accommodation of carbon atoms (radius $0.77 \AA$ ) results in some lattice strain, thus explaining why carbon's

\section{Table}

Interstice Sizes in the Face-Centered Cuhic Iron Lattice

$$
\begin{aligned}
& R_{6}=0.414 \mathrm{R} \text { (octatiedral position) } \\
& R_{4}=0.225 \mathrm{R} \text { (tetragonal) } \\
& R_{3}=0.155 \mathrm{R} \text { (trigonal constriction) }
\end{aligned}
$$

$R$ is the radius of the metal parent atom (which for iron is $1.26 \AA$ ), and $R_{X}$ is the maximum diameter of the interstitial site of crystallographic co-ordination number $x$.

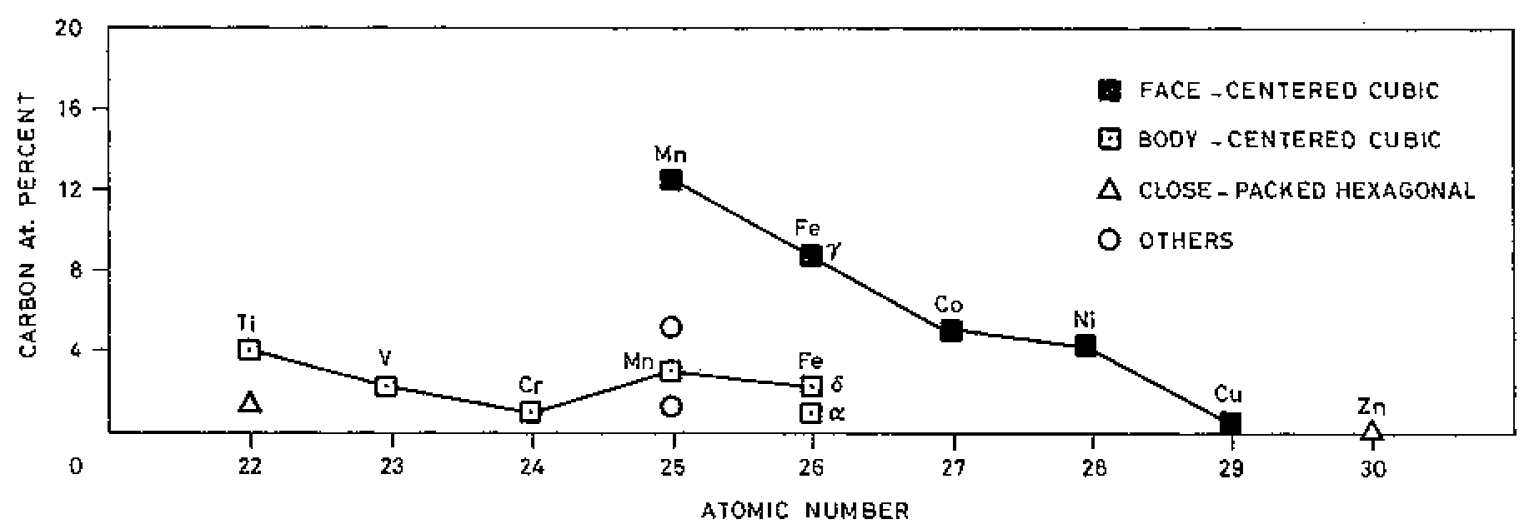

Fig. 1 Maximun solid solplility of interstitial carlon in the transition metals as a function of their atomic number and lattice structure 


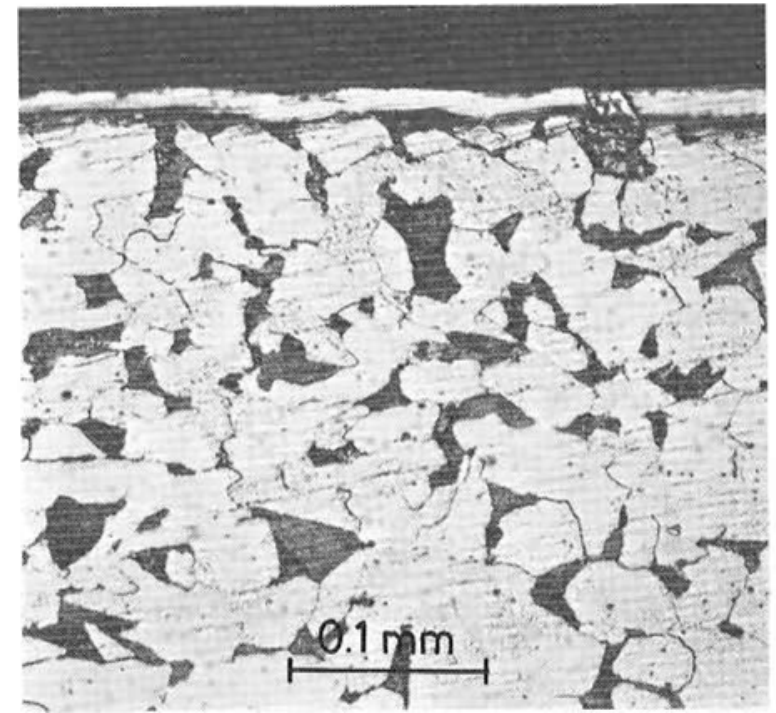

Fig. 2 Section through a sample of mild steel electrocoated with gold. The sample was subjected to a pack carburisation treatment for 10 hours at $910{ }^{\circ} \mathrm{C}$. There is no evidence of carbon penetration through the gold barrier coating

solubility in face-centred cubic iron (austenite) is only 2 per cent. Similar calculations, based on the corresponding interstice sizes in copper, which is likewise face-centred cubic, suggest that in theory carbon should be at least as soluble in copper than in iron, due to the slightly greater size of the interstices in copper.

Copper's barrier action to carburising must therefore be explained in terms other than geometrical factors and the strain energy associated with interstitial solute accommodation.

The solubility of carbon in various metals is shown in Figure 1. Metals in the first transition series show a steady decrease in carbon solubility with increase in the atomic number between manganese and zinc. The solubility change is explained in terms of the degree of filling of the $3 d$ electron energy level. An incompletely filled $3 \mathrm{~d}$ shell, caused by the energy overlap between the $3 \mathrm{~d}$ and $4 \mathrm{~s}$ states, allows easier acceptance of carbon's four valence electrons and therefore gives rise to enhanced solubility. Consequently, as the $3 \mathrm{~d}$ shell progressively fills across the series, the solubility of carbon decreases and finally is effectively zero in copper whose $3 \mathrm{~d}$ shell is full.

Since the carburisation-inhibiting action of copper could be explained in relation to that metal's atomic structure and position in the periodic classification, it was suggested that other elements in the same periodic group might exhibit similar carbon insolubility and therefore a 'stop-off' action. However, besides having the correct atomic structure, these metals if they are

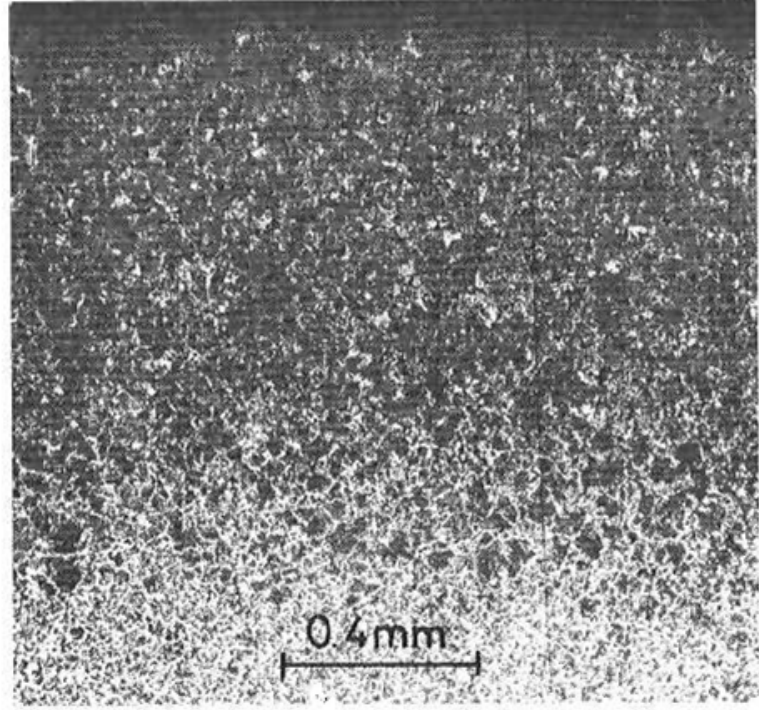

Fig. 3 Check sample of uncoated mild steel after pack carburisation. The carbon penetration has resulted in different microstructures at the surface (high carbon concentration) and at the core of the sample (no carbon enrichment)

to act as carburisation inhibitors, must fulfil other practical requirements - for example, they must be stable at carburising temperatures and amenable to electrodeposition. A review of possible metals showed that gold fulfilled all these requirements. With an atomic radius of $1.44 \AA$, it has interstices of comparable size to those in copper, but more importantly, it has a similar full d shell and one s electron. Further, its melting point, $1064^{\circ} \mathrm{C}$, precludes fusion during the hightemperature carburisation process.

In order to test gold's effectiveness as a 'stopoff', mild steel samples were coated on part of their surfaces with an electrodeposited layer of gold and then subjected to pack-carburisation for 10 hours at $910^{\circ} \mathrm{C}$. After this treatment, it was found by sectioning and metallographic examination, that the gold layer had effected a perfect 'stop-off' action as shown in Figure 2. Such complete inhibition of carburisation was all the more remarkable in view of the fact that the gold film was only some $0.009 \mathrm{~mm}$ thick. As a comparison, Figure 3 shows an uncoated specimen, which has fully carburised.

Although there seems to be little prospect of industrial application of gold in large scale carburising operations, the new insight now provided into its activity as a barrier to the diffusion of carbon could well stimulate interest into its activity as a barrier to the diffusion of other elements.

\section{Reference}

1 M. G. C. Cox, V. D. Scott and P. C. Thornton, Met. Sci., 1976, 10, 379-381 